\begin{tabular}{|c|}
\hline 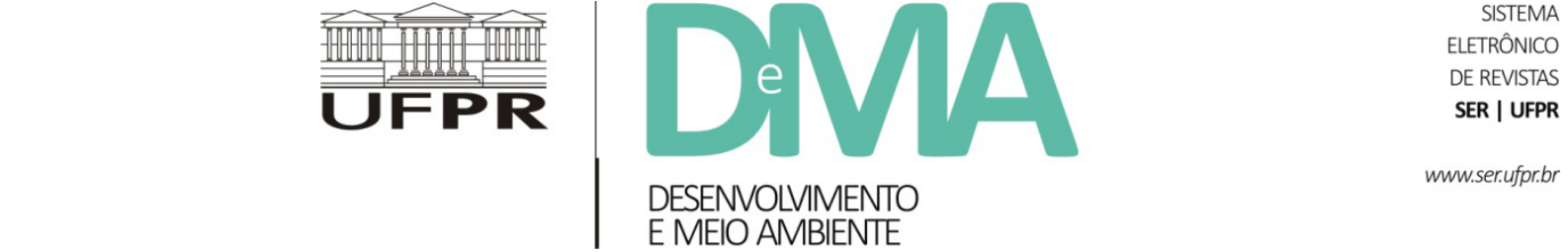 \\
\hline
\end{tabular}

\title{
Lixo flutuante na Baía de Guanabara: passado, presente e perspectivas para o futuro
}

\section{Floating Litter in Guanabara Bay: Past, Present and Future Perspectives}

\author{
Dandara BERNARDINO ${ }^{1}$, Barbara FRANZ ${ }^{*}$ \\ ${ }^{1}$ Programa de Pós-Graduação em Biologia Marinha, Universidade Federal Fluminense (UFF), Niterói, RJ, Brasil. \\ *E-mail de contato: barbara_franz@id.uff.br
}

Artigo recebido em 5 de junho de 2016, versão final aceita em 15 de agosto de 2016.

RESUMO: A poluição por lixo flutuante nos ambientes marinhos e costeiros é um grave problema em todo o mundo, causado geralmente pela gestão ineficiente de resíduos nas zonas costeiras, gerando sérios impactos na vida selvagem, como, por exemplo, morte por ingestão de lixo. O presente estudo tem como objetivo analisar, sob uma retrospectiva histórica e perspectivas para o futuro, o problema do lixo flutuante na Baía de Guanabara. Como metodologia, a análise do passado foi realizada partir da revisão bibliográfica e documental. A análise do presente foi baseada em dados de campo quanto aos itens de lixo flutuante coletados em estudos realizados nas praias de Icaraí, Charitas e São Francisco, em Niterói, na Praia do Flamengo, no Rio de Janeiro, e no Manguezal do Parque Natural Municipal Barão de Mauá, em Magé, e em informações atuais sobre as ações em relação ao lixo flutuante. As perspectivas para o futuro se baseiam nos planos de saneamento básico dos municípios localizados no entorno da Baía de Guanabara que estipularam metas para a despoluição da Baía. Desta forma, os resultados obtidos demonstram que, apesar dos esforços dos órgãos públicos para despoluir a Baía de Guanabara, o lixo dos municípios do entorno dela continua a chegar ao estuário. Reforça-se, no entanto, que ainda é cedo para determinar se esses programas serão, de fato, eficazes, pois há muitas ações a serem realizadas envolvendo tanto a conscientização da sociedade como a participação de todos os atores sociais envolvidos.

Palavra-chave: lixo flutuante; gestão de resíduos sólidos; Baía de Guanabara.

ABSTRACT: The pollution of marine and coastal environments by floating litter is a serious problem around the world, usually provoked by an inefficient waste management in the coastal areas, that may generate severe impacts in the wild life, for example death by waste ingestion. The present study has the goal to analyse, under a historical retrospective and future perspective, the floating litter problem at Guanabara's Bay. Therefore, the methodology for the historical analysis was done by a literature study. In turn, the present analysis was based on field data related to the floating litter on previous studies at the beaches of Icaraí, Charitas and São Francisco located at the city of Niterói, Flamengo beach on Rio de Janeiro and at the Mangrove of Barão de Mauá City’s Natural Park in Magé, respectively. Where samples were collected and current information about the actions related 
to the floating litter studied. The future perspectives were based on sanitation plans of municipalities around Guanaraba Bay that settle future goals to the pollution of it. In doing so, the results show that in spite of the public agencies efforts to depollute the Guanabara Bay, all the wastes produced by the surrounding municipalities keep reaching the estuary. It is worth mentioning that is too early to determine if these programs will be, in fact, effective and there are many different actions that need to be done including not only social awareness, but also the participation of all the social actors involved.

Keywords: floating litter; solid waste management; Guanabara Bay.

\section{Introdução}

Ao longo do tempo, os resíduos gerados nas primeiras civilizações não eram considerados motivos de preocupação, pois se tratavam de materiais de comparativamente rápida decomposição. Nos últimos 50 anos, por sua vez, houve estímulo ao rápido crescimento da produção de materiais sintéticos persistentes, alterando significativamente $\mathrm{o}$ tipo e a qualidade dos resíduos gerados. No modelo consumista atual, passou-se a produzir cerca de 1,3 bilhão de toneladas de lixo urbano por ano (ONU-BR, 2012). Associado ao atual estilo de vida da sociedade moderna, que leva ao aumento do consumo de descartáveis, o ser humano se torna o principal culpado pela crescente degradação dos oceanos (Araújo \& Costa, 2003).

$\mathrm{O}$ crescente consumo leva à grande produção de resíduos, que pode resultar em graves impactos negativos quando ocorre sua disposição inadequada. A "disposição final ambientalmente adequada" é definida pela Lei da Política Nacional de Resíduos Sólidos $n^{\circ} 12.305$ de 2010, no artigo $3^{\circ}$, como "distribuição ordenada de rejeitos em aterros, observando normas operacionais específicas de modo a evitar danos ou riscos à saúde pública e à segurança e a minimizar os impactos ambientais adversos" "Rejeitos", por sua vez, é definido nessa Política como "resíduos sólidos que, depois de esgotadas todas as possibilidades de tratamento e recuperação por processos tecnológicos disponíveis e economicamente viáveis, não apresentem outra possibilidade que não a disposição final ambientalmente adequada" (Brasil, 2010).

Segundo Tucci (2008), o processo de ocupação desordenada ocorreu em muitas áreas periféricas nas cidades urbanas da América Latina, as quais são geralmente desprovidas de infraestrutura tradicional de água, esgoto, drenagem, transporte e coleta de resíduos sólidos. Essa ocupação normalmente não foi acompanhada pela implantação ou pela melhoria de serviços de saneamento básico, destacando-se para este trabalho a "limpeza urbana e o manejo de resíduos sólidos", que correspondem, segundo a Lei que estabelece diretrizes nacionais para o Saneamento Básico n ${ }^{\circ} 11.445$ de 2007, ao "conjunto de atividades, infraestruturas e instalações operacionais de coleta, transporte, transbordo, tratamento e destino final do lixo doméstico e do lixo originário da varrição e limpeza de logradouros e vias públicas" (Brasil, 2007). Desse modo, o ineficiente gerenciamento deste serviço (por exemplo, falta de coleta ou realização da mesma em períodos irregulares, bem como destino final em vazadouro a céu aberto) leva à sua deposição em local inadequado.

A situação descrita é agravada quando os habitantes costumam lançar seus resíduos diretamente nos logradouros e nas vias públicas, ao invés de lixeiras, como foi observado no estudo de Mucelin \& Bellini (2008), por exemplo. O descarte inadequado de resíduos sólidos nas vertentes das encostas, nas ruas, nos sistemas de drenagem ou 
em terrenos abandonados pode agravar os riscos de alagamentos e deslizamentos, devido à presença de sobrecargas nas encostas, ao entupimento dos bueiros e ao assoreamento dos canais, sendo que os resíduos sólidos transportados pelos rios e pelo sistema de drenagem podem atingir os oceanos.

Os problemas causados pela presença do lixo no mar são complexos, segundo Jeftic et al. (2009), os quais apontam que estão diretamente relacionados à gestão ineficiente de resíduos, ao uso extensivo de recursos marinhos, à falta de infraestrutura e a atividades e condutas humanas indiscriminadas.

No Brasil, $50 \%$ do lixo gerado pelos municípios localizados em áreas costeiras do país é descartado de forma inadequada em lixões e aterros sanitários irregulares, geralmente situados sobre lençóis freáticos ou muito próximos a rios e ao mar (Conceição \& Scotti, 2013).

A ocupação do Brasil ocorreu a partir do litoral, levando à concentração de sua população nas zonas costeiras, onde importantes regiões metropolitanas se desenvolveram. Algumas delas se estabeleceram junto a baías, como Rio de Janeiro, Salvador, São Luís e Belém. A cidade do Rio de Janeiro (CRJ), capital do estado de mesmo nome e antiga capital federal, foi fundada na entrada da Baía de Guanabara (Figura 1) como posição estratégica para controlar o fluxo de mercadorias e pessoas da colônia, ocupando áreas de encostas e baixadas, as quais apresentavam brejos, pântanos e lagoas (Souza, 1997). Desde a chegada da família real portuguesa no ano 1808 , essa cidade cresceu e se fundiu com cidades vizinhas no entorno da Baía de Guanabara (BG), que hoje corresponde à Região Metropolitana do Rio de Janeiro (RMRJ), com uma população de 11.973 .505 habitantes, segundo a estimativa do IBGE (2014). O centro da RMRJ corresponde ao município-sede do Rio de Janeiro; ao norte, municípios conhecidos como "Baixada
Fluminense" (Nilópolis, São João de Meriti, Duque de Caxias e Nova Iguaçu); ao fundo da Baía de Guanabara, os municípios de Magé, Niterói, São Gonçalo, Itaboraí e Maricá; na divisa oeste da região, por sua vez, os municípios de Seropédica, Itaguaí e Mangaratiba (Dias, 2005).

A superfície da BG é de $377 \mathrm{~km}^{2}$, excluindo suas ilhas e considerando seu limite externo no arco formado pelas pontas de Copacabana. Na BG deságuam cerca de 50 rios e riachos, totalizando a vazão média de 200 mil litros (Amador, 1997). Suas bacias hidrográficas contribuintes compreendem uma superfície continental de $4.066 \mathrm{~km}^{2}$, segundo PAC/PDBG (2005), abrangendo 16 municípios dez integralmente e seis parcialmente--, coincidindo com significativa área da RMRJ.

$\mathrm{O}$ aumento populacional, conjugado ao crescimento econômico, desencadeou um aumento preocupante de resíduos sólidos, em volume e variedade, na RMRJ. Por exemplo, Franz (2011) verificou, no período entre 1999 e 2008, que o aumento da quantidade de resíduos sólidos (públicos e domiciliares) gerados na cidade do Rio do Janeiro pode estar relacionado com o aumento do PIB per capita na cidade em questão. De acordo Amador (2013), com o período de intensas chuvas, grandes volumes de lixo são introduzidos na Baía de Guanabara, geralmente transportados pelas descargas fluviais. Este autor aponta que em média 80 toneladas de lixo alcançavam diariamente a BG, dos tipos doméstico, hospitalar e industrial (Amador, 2013). Destaca-se que na RMRJ, no geral, muitos rios foram retificados, sendo atualmente utilizados como drenagens pluviais.

Atualmente, destaca-se que o lixo flutuante na RMRJ é observado facilmente em todos os seus ambientes aquáticos (praias, manguezais, lagunas, canais, rios), provocando uma impressão estética negativa. Na Figura 1, são mostradas praias que são 


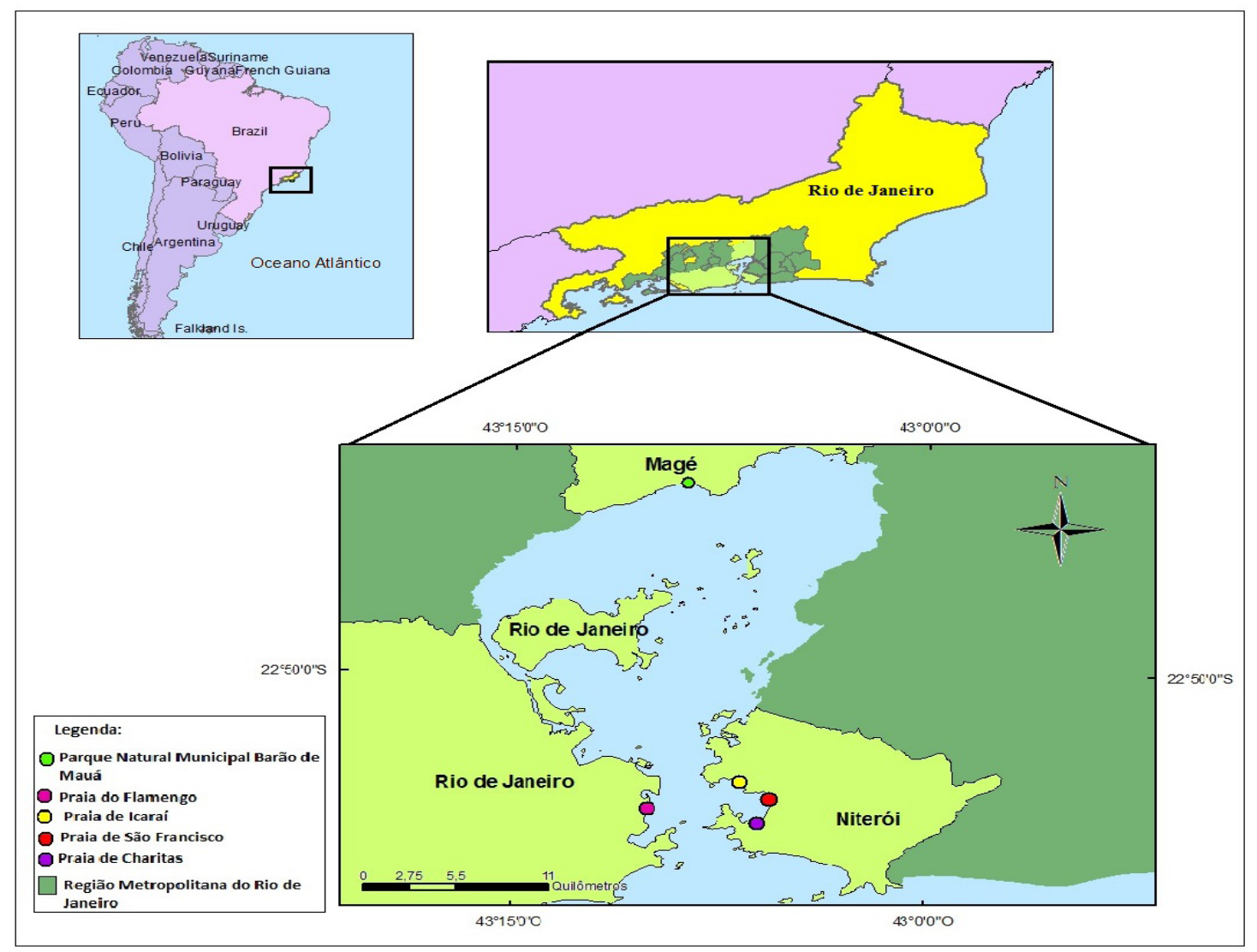

FIGURA 1 - Localização da Baía de Guanabara e identificação das áreas abordadas no estudo.

utilizadas pelos banhistas e onde frequentemente são encontrados itens de lixo flutuante (Hartz, 2014; Paiva \& Franz, 2014).

O objetivo do presente trabalho é analisar, sob uma retrospectiva histórica e perspectivas para $\mathrm{o}$ futuro, o problema da poluição por lixo flutuante na Baía de Guanabara, abrangendo aspectos quanto à forma como é gerado, seus danos e possíveis soluções para o problema.

Com os Jogos Olímpicos de 2016, a Baía de Guanabara se tornou um dos principais assuntos nas discussões sobre lixo flutuante, uma vez que foi palco das competições náuticas durante o evento.
Destaca-se também que o lixo flutuante pode prejudicar a atividade pesqueira, pois mistura-se ao pescado, dentro das redes (Teixeira \& Bessa, 2009). Por outro lado, essas atividades também podem gerar lixo marinho na BG quando as redes e outros equipamentos de pesca são abandonados, tendendo a provocar o emaranhamento de botos, como já foi identificado para a $S$. guianensis, conforme Barreto et al. (2010). Estes autores apontam que fragmentos de itens de lixo, por sua vez, também podem ser causadores de danos à saúde dos botos e outras espécies marinhas ao serem ingeridos. 


\section{Metodologia}

A base metodológica do trabalho é de natureza exploratória, em que se buscaram dados a partir de pesquisa bibliográfica, documental, amostragens e observação em campo sobre aspectos relacionados ao lixo flutuante na BG, principalmente quanto à gestão, à fonte e ao dano potencial.

O panorama do passado é baseado em pesquisa bibliográfica, buscando mostrar os fatores relacionados à geração de lixo flutuante que atingia a BG, desde a época do "Brasil-Colônia" a 2010, ano em que foi estabelecida, pela Lei ${ }^{\circ} 12.305$ de 2010, a Política Nacional de Resíduos Sólidos. A pesquisa bibliográfica é desenvolvida a partir de material já elaborado, constituído principalmente de artigos científicos e de livros (Gil, 2006). Destaca-se que em 2010 a cidade do Rio de Janeiro já havia sido escolhida como sede dos Jogos Olímpicos e Paraolímpicos de 2016 (fato que ocorreu em outubro de 2009), o que gerou expectativas quanto à despoluição da BG.

$\mathrm{O}$ enfoque do presente é discutir sobre os potenciais danos aos ecossistemas da BG e a fonte atual do lixo flutuante, baseado em estudos que envolvem amostragens de itens de lixo flutuante em ambientes de praia e mangue da BG, bem como analisar as ações para evitar ou diminuir o lixo flutuante na BG, incluindo aquelas no âmbito dos Jogos Olímpicos e Paraolímpicos Rio 2016. As perspectivas para o futuro se baseiam nos planos de saneamento básico dos municípios no entorno da Baía de Guanabara que estipulam metas para melhoria da gestão de resíduos, que, entre outros aspectos, visam reduzir a poluição na Baía.

Os dados obtidos por meio das amostragens de lixo flutuante no âmbito dos estudos de Paiva \& Franz (2014), Hartz (2014), Franz \& Hartz (2014) e Bernardino (2015) foram recalculados para o presente artigo visando definir categorias de lixo flutuante que refletem potenciais danos aos ecossistemas da BG ou sua atual fonte. Os estudos que envolvem as amostragens de itens de lixo flutuante foram realizados (Figura 1): nas praias de Niterói (Icaraí, São Francisco e Charitas), entre setembro e dezembro de 2013 (cinco campanhas de amostragens), relacionados à pesquisa de Paiva \& Franz (2014); na Praia do Flamengo, na cidade do Rio de Janeiro, entre janeiro e maio de 2014 (seis campanhas), relacionados aos estudos de Hartz (2014) e Franz \& Hartz (2014); e no manguezal do Parque Natural Municipal Barão de Mauá (PNMBM), no município de Magé, entre março e junho de 2015, relacionados também a Bernardino (2015). Todas as áreas estão localizadas na orla da Baía de Guanabara e o tipo de lixo que atinge esses ambientes é influenciado pela maré e pela vazão dos rios e canais contribuintes à $\mathrm{BG}$, que variam segundo as precipitações pluviométricas locais (Hartz, 2014; Paiva \& Franz, 2014; Bernardino, 2015). Dessa forma as categorias foram divididas para esta pesquisa segundo composição, tamanho e uso do item antes do descarte, mostrando-se, contudo, somente aquelas que são predominantes (em maior porcentagem). Para melhor compreensão, a categoria de plástico de $0,2 \mathrm{~cm}$ a $1 \mathrm{~cm}$ indica o dano, visto que é um tamanho passível de ser ingerido pela fauna e, como não é possível sua decomposição no trato digestivo, pode causar sua morte. Já a categoria "hastes flexíveis" indica que a fonte é doméstica, pois antes do descarte sustentava o pirulito ou era parte, juntamente com o algodão nas suas extremidades, de um cotonete.

A categoria de plásticos entre 0,2 a $1 \mathrm{~cm}$ compõe-se de fragmentos de plástico, sendo que os de $0,2 \mathrm{~cm}$ de diâmetro são identificados ao observar um fragmento pequeno colorido na areia 
da praia. Acima disso, a categoria maior que $1 \mathrm{~cm}$, correspondem a fragmentos maiores, de potes, de pacotes de biscoito, entre outros. A categoria "outros" representa resíduos de alumínio, parafina, têxtil, vidro, rejeitos da construção civil e papel.

A metodologia de campo, realizada nas praias de Icaraí, São Francisco, Charitas (em Niterói) e do Flamengo (no Rio de Janeiro), corresponde a amostragens na superfície da praia, seguindo a linha de maré (também denominada de "linha-do-deixa"), onde foram coletadas (antes da limpeza da praia pela empresa de limpeza pública do município), quantificadas e divididas em categorias. Foram realizadas entre cinco e dez amostragens durante cada campanha ao longo das praias estudadas, utilizando-se uma trena para medir o comprimento das mesmas. A definição do comprimento total dependeu da concentração dos itens de lixo marinho presentes: quando se encontravam itens com alta concentração, o comprimento amostrado ao longo da linha da maré foi de aproximadamente $2 \mathrm{~m} \mathrm{e}$ quando os itens estavam dispersos o comprimento foi cerca de $25 \mathrm{~m}$ (o que só ocorreu nas praias de Niterói).

No estudo de Bernardino (2015), foram realizadas cinco campanhas no Manguezal do PNMBM nos meses de março a abril de 2015. Em cada campanha foram realizadas a quantificação e a categorização dos itens depositados em duas parcelas previamente delimitadas na Orla da Baía de Guanabara, sendo que a primeira parcela possui $12 \mathrm{~m}^{2} \mathrm{e}$ a segunda $15 \mathrm{~m}^{2}$. Foram quantificados apenas itens acima de $5 \mathrm{~cm}$, em razão de haver muitos itens de tamanhos menores, impossibilitando a contagem dos mesmos. Ressalta-se que os itens com a possibilidade de identificação (embalagens de xampu, de manteiga, entre outros) foram classificados mediante a composição e o tamanho ou utilização antes do seu descarte. Isso foi realizado para permitir melhor interpretação dos dados quanto à fonte e ao perfil da pessoa que gerou esse lixo.

No presente artigo, todas essas categorias são apresentadas por meio de gráficos de setores segundo as categorias mencionadas, indicando potencial dano ao ecossistema da Baía de Guanabara ou sua fonte, e sob este enfoque estes dados são comparáveis.

\section{Lixo flutuante na Baía de Guanabara no passado}

A cidade do Rio de Janeiro (CRJ), segundo documentos analisados por Aizen \& Pechman (1985), era insalubre no início do século XVII, sendo que as ruas exalavam um forte mau cheiro. No contexto da análise desses autores, o hábito da população da Cidade do Rio Janeiro de dispor o lixo em canais ou nas suas margens ocorre desde o século XVII.

Houve algumas melhorias urbanas durante $\mathrm{o}$ século XVIII, como escoamento das águas pluviais, calçamento e limpeza de vias. Contudo, ainda não havia rede de esgotos e coleta de resíduos sólidos. Documentos de meados do século XVIII apontavam que os moradores da CRJ depositavam resíduos, denominados de "imundícies", em locais próximos às suas residências, como vias públicas, praias, lagoas e rios (Aizen \& Pechman, 1985). Ressalta-se que o termo "imundície" deixou ser utilizado quando, na segunda metade do século XIX, se passou a distinguir "lixo" (resíduos sólidos) de "águas servidas" (fezes e urina), quando estas passaram a ser coletadas separadamente através do esgotamento sanitário (Eigenheer, 2009).

Com a vinda da família real em 1808 para a CRJ, na ânsia de transformar a cidade num domicílio real, mangues foram aterrados, novas ruas foram abertas, casas foram derrubadas e calçadas, praças 
e ruas foram varridas. Foram baixadas posturas relativas à construção de casas, ao alinhamento das ruas, à preservação das fontes de água e também sobre o lançamento das imundícies (Aizen \& Pechman, 1985).

Em época de chuvas torrenciais, o sistema de drenagem transbordava, espalhando a imundície nele depositada e, em seguida, normalmente a CRJ sofria grave epidemia (Aizen \& Pechman, 1985; Abreu, 1997).

As primeiras posturas que se conhece do século XIX são basicamente normativas, assim como nos séculos XVII e XVIII. Isto é, definiam proibições e estabeleciam sanções quanto ao despejo do lixo nas vias públicas (Aizen \& Pechman, 1985). O crescimento populacional e a persistência de uma forma urbana exígua e colonial agravaram os problemas já existentes, como o precário estado sanitário da CRJ, caracterizado, entre outros aspectos, pelo despejo de matérias fecais e resíduos sólidos nas valas da cidade, bem como nos mangues, pântanos, praias e ruas (Gomes, 2005). Transportados à cabeça por escravos (os "tigres"), barris eram levados para os terrenos baldios ou para o mar, onde a imundície era despejada (Aizen \& Pechman, 1985).

Em 1847, a parte central da cidade do Rio de Janeiro foi beneficiada com a coleta de resíduos urbanos diária e dupla: pela manhã e pela tarde. Para a remoção do lixo acumulado nas praias, lugar onde era conduzido tudo o que se removia das ruas, a Câmara Municipal fez construir três saveiros. Desde essa época, todo o lixo que se conduzia para as praias era recebido por esses saveiros, que por sua vez eram rebocados por um vapor, e, por fim, lançado no lugar indicado pela capitania do porto no mar ou era depositado a sotavento da Ponta do Caju (Aizen \& Pechman, 1985).
A expansão da CRJ ocorreu à custa de intermináveis aterros e dissecamentos ocorridos durante mais de 300 anos até o século XIX. Lagoas e pântanos foram aterrados com entulho e lixo, ou seja, além da construção de inúmeras valas que contribuíram para o enxugamento do solo, os dejetos da própria cidade do Rio de Janeiro viabilizaram sua expansão sobre o brejo, sobre as lagoas e sobre o mar (Souza, 1997).

A partir de 1850, considerando as inundações em períodos de tempestades, algumas obras urbanas foram realizadas para evitar epidemias (febre amarela e outras). Foram construídos aterros, solos foram nivelados (para evitar a formação de poças), bem como foram realizados a drenagem superficial, a disposição final adequada dos dejetos urbanos, o aumento do abastecimento de água e a desconcentração urbana (Abreu, 1997).

No final do século XIX e início do século XX, o Estado começa a assumir os serviços de saneamento como atribuição do poder público, transferindo, porém, os mais importantes deles para a iniciativa privada, principalmente as de capital inglês, que na época tinham hegemonia no mercado brasileiro (Rezende \& Heller, 2008). The Rio de Janeiro City Improvements Company Limited foi uma concessionária inglesa constituída em 1862, sendo as primeiras obras inauguradas em 1864 . A cidade do Rio de Janeiro foi a primeira capital brasileira e a quinta do mundo a possuir um sistema de coleta de esgoto (Gomes, 2005; Rezende \& Heller, 2008). Depois de várias tentativas com outros concessionários, o serviço de esgotos eliminou de uma vez por todas a questão do despejo dos dejetos (Aizen \& Pechman, 1985).

As matérias fecais, o lixo sólido e as águas pluviais, que comumente eram lançados nas valas, passaram a ter fins separados a partir da construção dos encanamentos de esgotos, dando origem a uma 
série de redes e sistemas, até então inexistentes, no espaço urbano carioca. As valas foram progressivamente substituídas por galerias exclusivas de águas pluviais e o lixo, pela primeira vez na história da cidade, teve um destino final específico: a Ilha da
Sapucaia (Gomes, 2005). Essa ilha, que recebeu detritos e entulho de 1893 a 1954, foi incorporada a outras, formando a Ilha do Fundão (Figura 2), onde está instalada atualmente a Cidade Universitária UFRJ (Gamboa, 2007).

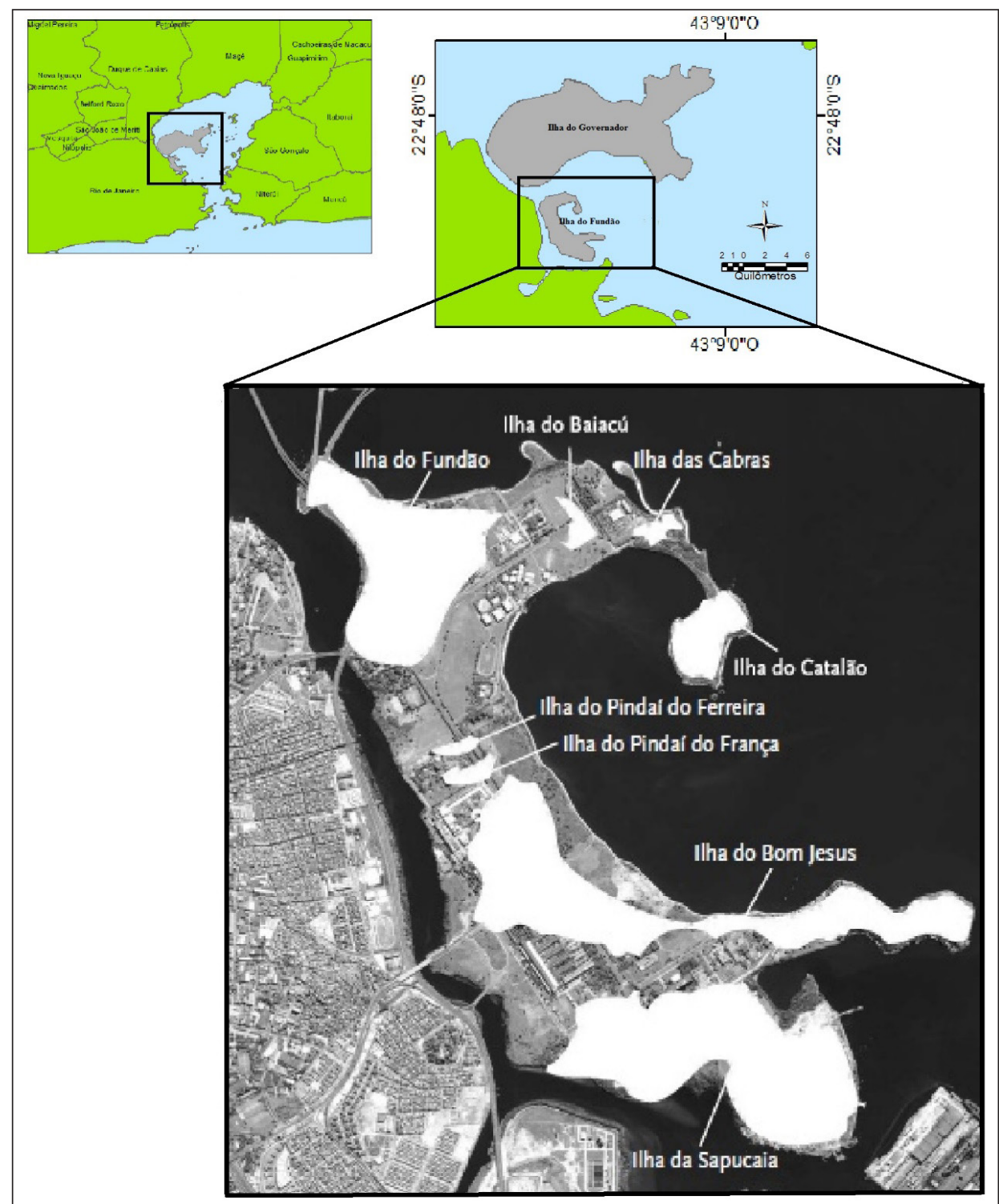

FIGURA 2 - Montagem das ilhas originais sobre a atual Ilha do Fundão. FONTE: Gamboa (2007). 
O lixo das casas particulares era tirado por carroceiros, mediante uma mensalidade, sendo que esse serviço em algumas casas não era feito diariamente, gerando grande inconveniente. Em 1883, o transporte de lixo pelo mar era deficiente e havia muito lixo sendo despejado na Ilha de Sapucaia, o que tornava a BG poluída (Aizen \& Pechman, 1985).

Em 1902, iniciou-se a gestão do Prefeito Pereira Passos, que instituiu uma política higienista, demolindo na área central as habitações consideradas insalubres. O crescimento demográfico não foi acompanhado pela desconcentração do emprego. A partir das ações do prefeito Passos, cuja gestão também visava reformar e homogeneizar a cidade, uma multidão, pobre e desabrigada, passou a ocupar encostas e manguezais na área periférica da cidade, que correspondia às áreas financeiramente acessíveis mais próximas aos locais de trabalho. Dessa forma, a remodelação da cidade desencadeou o processo de favelização (Abreu, 1997; Ferreira, 2006).

Mulas e burros eram a força motriz que movia as pesadas carroças repletas de lixo, levando à fadiga desses animais. O Serviço dispunha, em 1906, de 1.084 animais, já insuficientes para o trabalho de limpeza da cidade. Assim, a título de experiência, são adquiridos dois autocaminhões, mas, no ano seguinte, os serviços voltam a ser feitos exclusivamente por tração animal (Aizen \& Pechman, 1985).

Em 1907, a Ilha de Sapucaia, que era próxima do litoral, na ponte do Caju, recebia diariamente 560 toneladas de lixo. Durante marés altas, as partes do vazadouro que não estavam consolidadas eram retiradas pelo mar, criando dificuldades para sua manutenção. Em 1919, a obstrução da BG pelo lixo da Sapucaia constitui-se num grande problema, de modo que até mesmo embarcações poderiam vir a encalhar (Aizen \& Pechman, 1985).
Planos para resolver o problema do destino final, por meio da incineração do lixo, foram feitos em 1907, 1911, 1915, 1919 e 1922. No final da década de 1920, os grandes hotéis e os edifícios de apartamento aumentaram em muito o serviço de coleta domiciliar. Desse modo, a Societé Anonyme du Gaz introduziu no mercado os primeiros incineradores para edifícios, uso que foi se generalizando em todas as construções, principalmente a partir de 1950, sendo desativados na década de 1970, devido à poluição ambiental que produziam (Aizen \& Pechman, 1985).

Em 1924, foram adquiridos 10 autocaminhões, cuja capacidade de carga, correspondia a 50 carroças das antigas. Com os novos caminhões de remoção do lixo, a higiene da cidade melhorou sensivelmente (Aizen \& Pechman, 1985).

A partir dos anos1950, rios como Irajá e São João de Meriti (na foz dos quais atualmente estão instaladas as Ecobarreiras) começaram a ser utilizados como vazadouros de resíduos sólidos, além de sofrerem com despejos de poluentes industriais e de esgotos (Nasser, 2001).

A administração da limpeza urbana passou por diversas empresas, sendo que em 1975 foi fundada a Companhia Municipal de Limpeza Urbana (COMLURB), que passou a gerir a limpeza urbana da cidade. A destinação desses resíduos só começou a ser realizada de forma adequada a partir da década de 1970, com a criação do aterro de Gramacho (município de Duque de Caxias), adequado na época, mais precisamente situado na orla da Baía de Guanabara, ocupando uma área de aproximadamente 1,3 milhão de $\mathrm{m}^{2}$ (Eigenheer, 2009; Bastos, 2005).

Um dos grandes marcos históricos para redução da poluição da BG pelo poder público, inclusive por resíduos sólidos, foi o Programa de Despoluição da Baía de Guanabara, mais conhecido por sua sigla 
"PDBG". Esse programa foi iniciado em 1994 e financiado pelo Banco Mundial e pelo Japan Bank for International Cooperation (JIBIC), apresentou-se como o maior conjunto de obras de saneamento dos últimos vinte anos no Estado do Rio de Janeiro, tendo por objetivos gerais recuperar os ecossistemas ainda presentes no entorno da Baía de Guanabara e resgatar gradativamente a qualidade das águas e dos rios que nela deságuam, com a construção de sistemas de saneamento adequados em municípios situados no entorno da Baía. O PDBG, no final de 2001, segundo Britto (2003), não logrou seus objetivos de ampliar o acesso e melhorar significativamente a qualidade desses serviços e, nesse sentido, recuperar ecossistemas e melhorar a qualidade das águas da BG. Estas são metas que ainda estão muito longe de serem alcançadas.

Com o fim de deter o avanço do lixo flutuante à Baía de Guanabara, o governo estadual do RJ lançou em 2004 o projeto Ecobarreira, que consiste na instalação de barreiras na transversal da foz de seus rios contribuintes, denominadas de Ecobarreiras. Este projeto visa à "coleta de resíduos sólidos recicláveis e não recicláveis descartados nos corpos hídricos do Estado do Rio de Janeiro, objetivando melhor qualidade das águas dos corpos hídricos estaduais" (Febracom/ASSERJ/Inea, 2009). A coleta do lixo retido nas Ecobarreiras é realizada por "Ecogaris", que fazem parte de cooperativas associadas ao projeto.

Ressalta-se que embora a "gestão do lixo" tenha sido citada como um dos elementos de enfoque (do total de quatro) do programa de sustentabilidade e de meio ambiente dos Jogos Olímpicos e Paraolímpicos Rio 2016, segundo Dossiê do Comitê de Candidatura - volume 1 (2009), esse documento nada mencionou quanto ao lixo flutuante presente na Baía de Guanabara, mesmo sendo palco da modalidade de vela nos Jogos Olímpicos.

\section{Lixo flutuante na Baía de Guanabara: presente e perspectivas para o futuro}

A gestão de resíduos sólidos na Região Metropolitana do Estado do Rio de Janeiro possui uma efetividade baixa no que concerne aos programas de despoluição da Baía de Guanabara (Britto, 2003), situação comparativa apontada pelo Secretário Estadual do Ambiente em 2015, quando comentou que "infelizmente o sistema de coleta de lixo no entorno da Baía de Guanabara, atribuição dos municípios, não tem se mostrado eficiente" (INEA, 2014). Dessa forma, uma gestão eficaz de resíduos nos municípios do entorno da BG é um dos principais fatores que evita ou propicia a redução da entrada de lixo nas águas da Baía, que comumente ocorre por meio das descargas continentais.

Os principais danos que os itens de lixo flutuante na Baía de Guanabara desencadeiam são: atrapalha as atividades de esportes náuticos, representa um perigo aviário ao tráfego aéreo (pois atraem os urubus), impede o desenvolvimento de manguezais (o plástico, por exemplo, sufoca as mudas de espécies vegetais) e favorece o assoreamento da Baía de Guanabara (Franz, 2011). Além desses danos, identifica-se que pescadores, aquicultores, marisqueiros e outras comunidades que tiram seu sustento dessa região se encontram prejudicados pela falta de espécies.

Visando à despoluição da $\mathrm{BG}$, somada ao fato de que a presença do lixo na $\mathrm{BG}$ pode trazer danos à saúde dos atletas nos Jogos Olímpicos e Paraolímpicos de 2016 no Rio de Janeiro, algumas ações foram planejadas pelo Comitê Olímpico Internacional (COI) e implantadas pelo Governo do Estado do Rio de Janeiro. São elas, as Ecobarreiras, os Ecobarcos (para recolher o lixo flutuante na BG) e a construção de Unidades de Tratamento de Rios (UTR), que visam ao tratamento das águas de rios que deságuam na Baía de Guanabara (Rio 2016, 2013). 
Com o evento dos Jogos de 2016, a Baía se torna ainda mais importante, ganhando visibilidade no Brasil e no mundo. No Relatório de Sustentabilidade dos Jogos Olímpicos e Paraolímpicos de 2016 (Rio 2016, 2014), o qual discursa sobre como as iniciativas de sustentabilidade estão sendo incorporadas ao planejamento desse evento, é falado sobre a "Pegada Ambiental Reduzida", que seria a redução dos impactos negativos ao meio ambiente causados pela realização dos jogos. Nessa Pegada, um dos objetivos especificados na página 33 é a "Conservação e Recuperação Ambiental", contudo, no decorrer do documento, a parte de recuperação não é destacada, indicando que a recuperação dos ambientes já degradados a fim de que os Jogos ocorram em um ambiente saudável não é uma prioridade.

Ainda segundo o Relatório de Sustentabilidade (Rio 2016, 2014, p. 75), os objetivos na parte de resíduos são: "Gerenciar os resíduos sólidos com responsabilidade" e "implementar critérios para uso racional dos recursos, eficiência e minimização dos impactos ambientais" em todas as fases de preparação e instalação das estruturas temporárias e durante a ocorrência dos Jogos, de forma a criar oportunidades de legado dentro do contexto particular da cidade do Rio de Janeiro em relação aos seus próprios resíduos. No decorrer do documento, é possível observar diversos objetivos e metas para a mitigação dos impactos negativos nos ecossistemas, mas pouco foi visto realmente acontecer na prática.

O Projeto Ecobarreiras foi suspenso em março de 2015, sendo retomado em julho de 2015 pela Secretaria Estadual do Ambiente (SEA), quando previu ao todo 17 Ecobarreiras para os Jogos Olímpicos de 2016, com estruturas fortes, e com um sistema mecânico de retirada do lixo acumulado (Quaino, 2015). Dessas 17, duas localizam-se no município de São Gonçalo (fixadas nos rios Brandoas e Bomba), que são equipamentos de contenção, com 12 metros cada e capacidade para reter aproximadamente 30 toneladas de materiais recicláveis e 200 toneladas de lixo (Prefeitura de São Gonçalo, 2015). Os projetos de limpeza consumiram R $\$ 10$ bilhões nos últimos 20 anos, sem sucesso (Quaino, 2015).

Em relação às Ecobarreiras, Franz (2011) identificou os entraves na sua operação, que abrangem: o custo de manutenção; a dificuldade de remoção do lixo presente nos cursos d'água, dada sua grande quantidade (a qual não tem diminuído com o tempo, apesar das ações de educação ambiental); a coleta de materiais volumosos encontrados nos rios (como, por exemplo, móveis e eletroeletrônicos); a coleta do material não reciclável acumulado junto ao Ecoponto por empresa que presta esse serviço; as frequentes "aberturas" das Ecobarreiras dos rios Irajá e São João do Meriti; e a insegurança na Ecobarreira do Canal do Cunha.

O Secretário Estadual do Ambiente, em nota no site da SEA, admitiu que o programa das Ecobarreiras é paliativo e não retém todo o lixo, pois parte passa por baixo da barreira ou se deposita no fundo; além disso, outro problema identificado foi a fragilidade do material que compõe as barreiras, que é facilmente rompido. Buscando solucionar esse problema, a SEA reformulou o programa em 2015, trocando por Ecobarreiras compostas por material mais resistente (SEA, 2015).

Resultados do estudo mostram que, apesar da implantação de programas para diminuir a poluição da BG, a presença de lixo flutuante ainda é preocupante.

As porcentagens mais importantes de categorias de itens de lixo flutuante encontradas são apresentadas nas Figuras 3, 4 e 5. Ressalta-se que não foram encontrados, em nenhuma amostragem, itens com informações em língua estrangeira no rótulo, indicando que não houve influência do descarte de embarcações. 


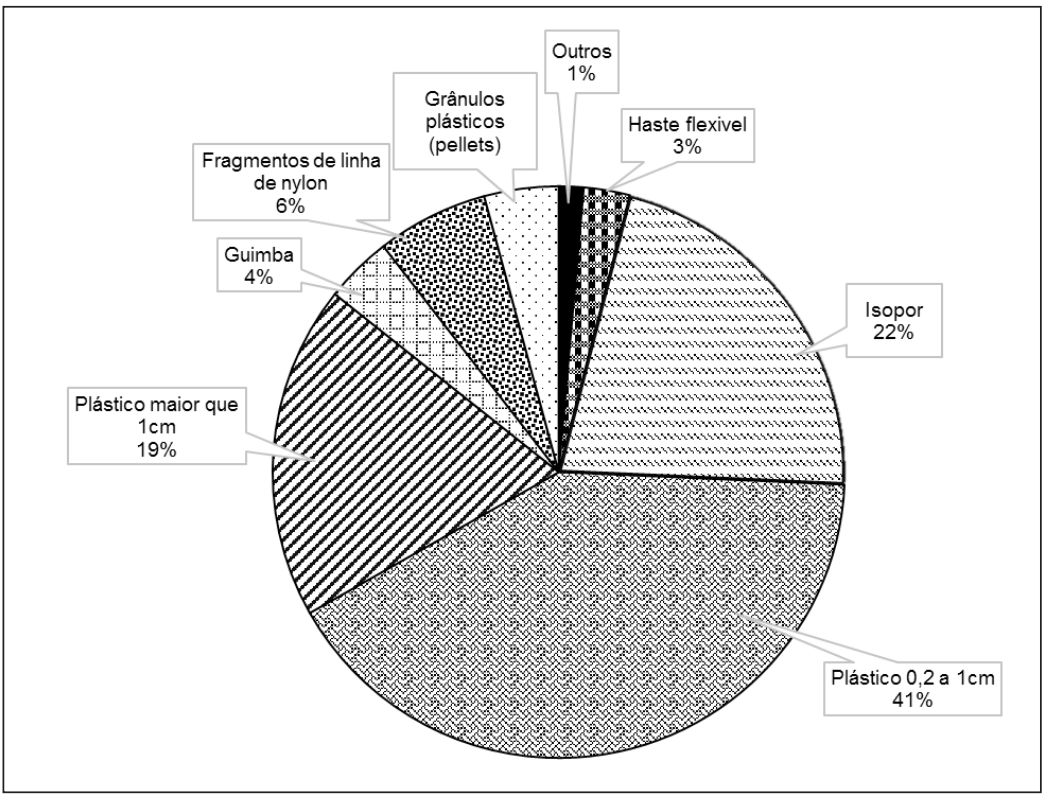

FIGURA 3 - Percentual da composição do lixo flutuante presente na Praia do Flamengo no Rio de Janeiro.

FONTE: elaboração própria baseada em dados do estudo de Hartz (2014).

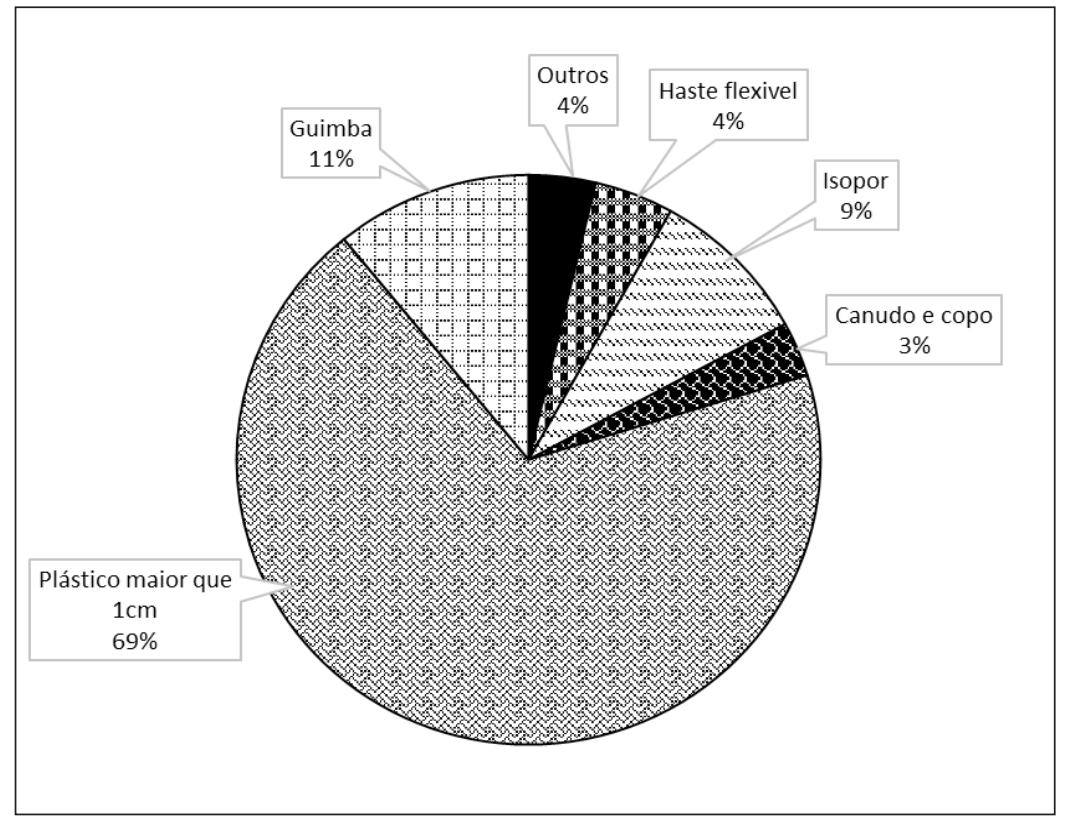

FIGURA 4 - Percentual da composição do lixo flutuante presente nas praias de Niterói, na Baía de Guanabara (Praias de Icaraí, São Francisco e Charitas).

FONTE: elaboração própria baseada em dados do estudo de Paiva \& Franz (2014). 


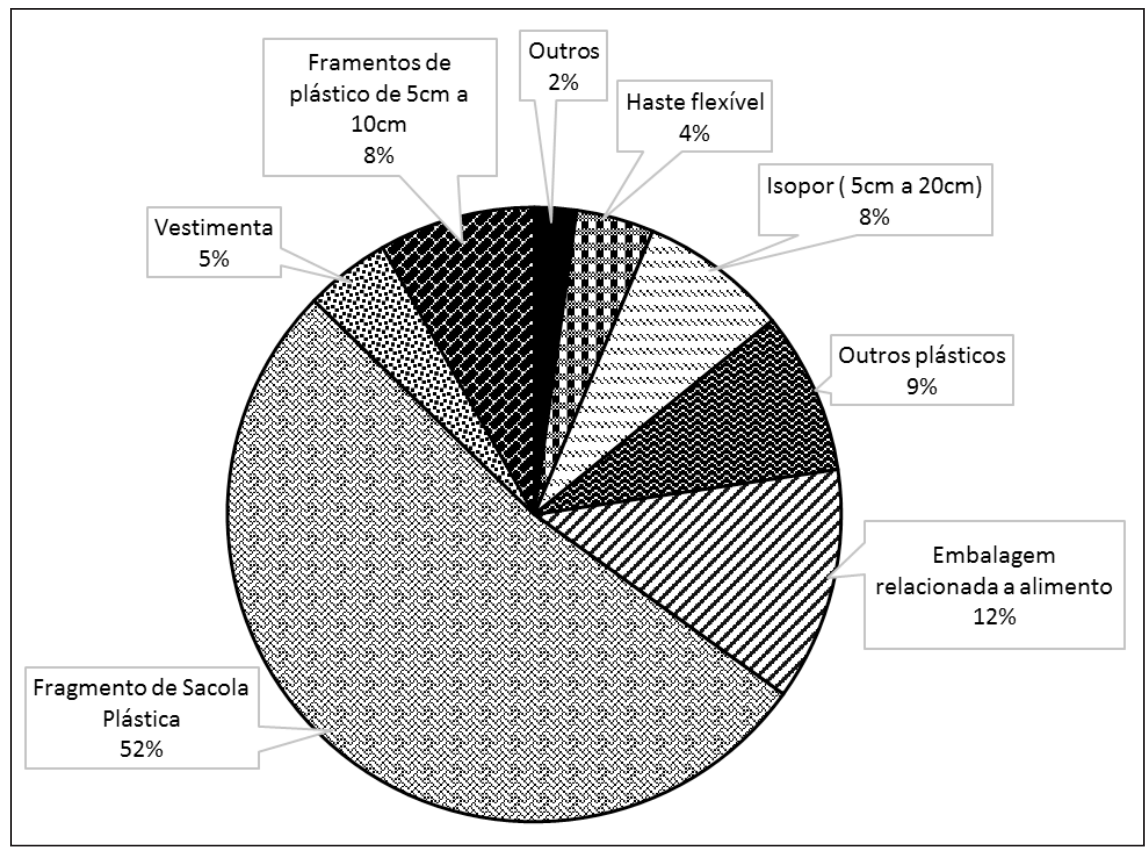

FIGURA 5 - Percentual da composição do lixo flutuante presente no Manguezal no Parque Natural Municipal Barão de Mauá, em Magé.

FONTE: elaboração própria baseada em dados do estudo de Bernardino (2015).

O plástico correspondeu ao material mais abundante, variando de $71 \%$ a $83 \%$ do total de itens amostrados (Figuras 3, 4 e 5). Outros estudos também apresentaram essa característica, como Neves et al. (2011), em Vila Velha/ES; Portz et al. (2011), em estudos no litoral norte do Rio Grande do Sul; Vieira et al. (2011), no Manguezal da Ilha de Santa Catarina; Ivar do Sul et al. (2009), nas praias de Fernando de Noronha, demonstrando que existe uma frequência da presença desse material nos ambientes costeiros do país.

Nota-se, mediante a observação dos gráficos (Figuras 3, 4 e 5), que o ambiente deposicional tende a determinar a forma e o tamanho dos materiais encontrados em maior quantidade. No caso do plástico, no manguezal do PNMBM (ambiente com menor energia deposicional entre as áreas pesquisadas), encontraram-se muitos itens menores que $1 \mathrm{~cm}$, não sendo possível quantificar, como foi apontado na metodologia.

Destaca-se que esse manguezal, além de fazer parte de um Parque Natural Municipal, encontra-se próximo à Estação Ecológica da Guanabara (ESEC da Guanabara), que é a umas das principais unidades de conservação na BG. A ESEC da Guanabara possui em sua área a presença de manguezal primário altamente preservado, assim como de espécies ameaçadas de extinção, como Aninga aninga (ave biguatinga), Dendrocygna bicolor (ave, marreca-caneleira) e Caiman latirostris (jacaré do papo 
amarelo) (Batista \& Roberto, 2009). De acordo com os mesmos autores, a ESEC ainda faz parte da zona núcleo da Reserva da Biosfera da Mata Atlântica (RBMA) e compõe, juntamente com outras Unidades de Conservação fluminenses, um importante complexo de áreas protegidas.

$\mathrm{Na}$ amostragem do manguezal no PNMBM se destaca a categoria fragmentos de sacola plástica (52\% - Figura 5), indicando que as sacolas, ao atingirem essas áreas, tendem a enroscarem-se nas árvores de mangue e fragmentarem-se durante a subida e descida da maré. No manguezal, a predominância dos itens era de plástico, os quais possuem características indicando sua origem doméstica.

Outros estudos indicaram também a representatividade do item, como foi o caso, por exemplo, de Belarmino (2014), em seu estudo no manguezal no rio Potengi, em que "sacolas plásticas" representaram $81 \%$ do total de itens, e de Baptista Neto \& Fonseca (2011), na Baía de Guanabara, onde, dos $70,6 \%$ do plástico quantificado, $56,5 \%$ era composto por sacolas plásticas. Esse item não é preocupante apenas no Brasil, inclusive no ano de 2005 o Departamento de Meio Ambiente da Austrália reconheceu que as sacolas plásticas representam uma grande preocupação devido a sua vasta quantidade nos mares (UNEP, 2005).

A predominância desse material pode estar relacionada ao intenso consumo do plástico, em virtude da sua grande aceitação como embalagem de alimentos industriais, o que se deve tanto à sua versatilidade e capacidade de armazenar adequadamente os produtos quanto à capacidade de evitar danificação do produto, reduzindo assim o risco de infecção e o desperdício de alimentos.

Nas praias de Niterói, os resultados indicaram que não foram encontradas quantidades representativas de resíduos menores que $1 \mathrm{~cm}$, sendo importante destacar que foi encontrado $69 \%$ de plástico maior que $1 \mathrm{~cm}$, contrastando com a Praia do Flamengo, onde foi quantificado $19 \%$ nesse tamanho (Figura 4). Nessa praia predomina a categoria plástico 0,2 a $1 \mathrm{~cm}$ de diversas cores, indicando que são originários da fragmentação de diferentes produtos plásticos, sendo possível ser de material de limpeza, higiene, brinquedo, utensílios do lar, entre outros. Esse resultado mostra seu potencial de degradação do meio ambiente, sendo a causa de morte de muitas espécies marinhas e costeiras (Araújo \& Costa, 2003).

Resultados da categoria isopor mostram que também representa um material preocupante em termos de poluição, destacando que, na Praia do Flamengo, 22\% de todos os itens encontrados são dessa classe (Figura 3). O isopor possui baixa densidade e alta resistência mecânica, além de absorver pouquíssima água (Macedo et al., 2011). Essas características permitem que esse material possa ficar por muito tempo flutuante na água e seja levado por longas distâncias. No manguezal, esse material tende a se misturar no sedimento, dificultando o seu transporte. Nesse contexto, no estudo de Bernardino encontrou-se $9 \%$ de fragmentos maiores que $5 \mathrm{~cm}$ de diâmetro (Figura 5) e no estudo de Hartz (2014) a maior parte não ultrapassou $2 \mathrm{~cm}(19,7 \%$ - Figura 3), indicando o grande potencial poluidor desse material em razão de sua característica de fragmentar-se facilmente.

A categoria embalagens plásticas relacionadas a alimentos (12\% - Figura 5) indica a disposição inadequada de resíduos domésticos nos cursos d'água afluentes da BG ou próximo deles, como foi observado por Franz (2011), que quantificou 1.394 itens encontrados dentro de sacolas fechadas junto às Ecobarreiras. 
A categoria guimba (Figuras 3 e 4) corresponde a $11 \%$ dos itens do estudo de Paiva \& Franz (2014) e 4\% do estudo de Hartz (2014), apontando sobre o mau hábito da população de lançar este resíduo inadequadamente. Isso ocorre também com outros resíduos, principalmente em vias públicas, os quais tendem a ser transportados após uma chuva, podendo atingir a Baía Guanabara pela drenagem urbana. Destaca-se que a prefeitura do município do Rio de Janeiro colocou em vigor a aplicação de multas previstas na Lei $n^{\circ} 3.273$ de 2001 de Limpeza Urbana para quem jogar lixo em vias públicas. Essa medida faz parte do programa lixo zero implantado no município para reduzir a disposição inadequada do lixo pela cidade.

Encontraram-se 4\% de Grânulos plásticos (também conhecidos como Pellets ${ }^{2}$ ), como mostra Figura 3. Esse item se destaca em função de não ser oriundo de desintegração física ou degradação de matérias manufaturadas, pois a forma arredondada não reflete abrasão (Gregory, 1983). Em geral, os pellets são a matéria-prima para a fabricação de produtos plásticos, ou seja, são o ponto de origem na cadeia produtiva de diversos materiais e utensílios de consumo da sociedade (Falcão \& Souza, 2014). Os grânulos de plástico podem ser perdidos no processo de armazenagem ou transporte e chegar aos ambientes costeiros por meio de descargas continentais, arrastados por correntes de maré, entre outros (Vedollin, 2014). Holmes et al. (2012) apontam que pequenos plásticos (como o caso desses grânulos) possuem o potencial de transportar metais a distâncias consideráveis. A associação de metais traços com plásticos tem implicações para sua transferência na cadeia alimentar de invertebrados, peixes, aves e mamíferos quando esses ingerem plásticos confundindo-os com alimentos (Holmes et al., 2012).

Itens relacionados às atividades pesqueiras também foram encontrados nas amostragens ao longo da praia do Flamengo, representando $6 \%$ do total de itens quantificados (Figura 3). Resíduos oriundos de atividades pesqueiras são comuns de serem encontrados nas pesquisas com foco em lixo marinho, representando uma fonte de poluição difusa, como também foi observado no documento da UNEP (2005), Marine Litter: An Analytical Overview. Jones (1995) destaca que as redes de emalhar configuram o tipo de resíduo de pesca mais preocupante para a biota. De acordo com a UNEP (2009, p. 23), de modo grosseiro se estima que $10 \%$ do lixo marinho do mundo possui origem de atividades de pesca.

Os resultados do estudo (Figuras 4 a 5) mostram que ainda há muito material reciclável chegando à Baía de Guanabara, como, por exemplo, o isopor e o plástico. No entanto, isso pode ser justificado por duas razões: a primeira consiste em que muitas vezes o valor do quilograma não compensa para o catador; a outra razão é que a estrutura e a quantidade de postos de coleta ainda não são satisfatórias, associadas à falta de orientação adequada. Destaca-se que garrafas PET e latas de alumínio são itens raramente encontrados nos ecossistemas da Baía de Guanabara, o que pode estar relacionado ao valor de venda desses materiais. Bernardino (2015) encontrou, por exemplo, apenas um item de PET e uma lata de alumínio.

O Pacto pela Reciclagem em desenvolvimento pela SEA e pelo Instituto Estadual do Ambiente (INEA) reuniu algumas ações e programas para ampliar a reciclagem de lixo, com o fim de reduzir

1 Guimba: parte que resta do charuto ou cigarro, depois de fumado (Ferreira, 2008 p. 272).

2 Pellets são pequenos grânulos, geralmente com a forma de um cilindro ou de um disco com um diâmetro de poucos milímetros (Takada, 2006). 
também a quantidade de lixo que chega aos aterros sanitários (SEA, 2015).

Outra medida importante é o Plano de Saneamento Ambiental Municipal (PSAM), que apoia a elaboração dos Planos Municipais de Saneamento Básico (PMSBs), que por sua vez têm como objetivo dotar os municípios do entorno da Baía de Guanabara de instrumentos e mecanismos que permitam a implantação de ações articuladas, duradouras e eficientes para o acesso ao saneamento básico, para os municípios que margeiam a BG. Dessa forma, a poluição da Baía por resíduos sólidos e efluentes teria uma redução brusca, sustentando a pouca qualidade que o ambiente dispõe atualmente (PSAM, 2015).

O PSAM foi criado em 2011 pelo decreto 42.931/2011 e esse programa beneficia 15 municípios do Estado do Rio de Janeiro, com projetos de esgotamento sanitário, buscando ampliar a rede de coleta e tratamento de esgoto, de $30 \%$ a $60 \%$ no Estado (SEA, 2013). O programa é coordenado por uma Unidade Executiva do PSAM, presidida pela Secretária de Estado do Ambiente. Para que o programa funcione de forma eficaz, é preciso que seja implantado contemplando os quatro eixos do saneamento básico.

O PMSB, além de contribuir para a despoluição da Baía de Guanabara, também possui o objetivo de atender a Lei 11.445 de 2007, que estabelece diretrizes nacionais sobre Saneamento Básico. Para tal, foi estipulado que os municípios do Estado do Rio de Janeiro elaborem até 2017 seus planos de Saneamento Básico, que devem ser compatíveis com os Planos de Bacia Hidrográfica, Planos Diretores Municipais, dentre outros instrumentos de ordenação territorial (PMSB, 2016).

A análise do conteúdo dos PMSB quanto aos principais problemas de gestão de resíduos sólidos que geram degradação do meio ambiente e medidas futuras previstas de gestão que poderia diminui-la é apresentada na Tabela 1, sendo que os dados estão disponíveis em PMSB (2016).

$\mathrm{Na}$ Tabela 1, ressalta-se a disposição inadequada de resíduos em vias públicas, rios e/ou terrenos baldios em Cachoeira do Macacu, Guapimirim, Nilópolis, São Gonçalo e São João de Meriti. Esses municípios também apontam problemas com disposição inadequada de resíduos de construção civil. Destaca-se que a Lei $n^{\circ} 4.191$ de 2003, que dispõe sobre a Política Estadual de Resíduos Sólidos, proíbe o lançamento de resíduos sólidos em locais como: praias, mananciais (e suas áreas de drenagem), cursos d'água, lagoas, áreas de várzea, bueiros e em diferentes sistemas (tais como de drenagem de águas pluviais, de esgotos, de eletricidade, de telefone) (Rio de Janeiro, 2003).

A Tabela 1 mostra também que há uma previsão de implantar ou ampliar programas de coleta seletiva em Cachoeira do Macacu, Guapimirim, Rio Bonito, São Gonçalo e São João de Meriti. Por meio das informações da Tabela 1, também se observam melhorias na disposição final dos resíduos com o encerramento de vazadouros a céu aberto em Cachoeira do Macacu, Guapimirim, Magé e São Gonçalo. Essas medidas previstas pelos municípios estão em conformidade com a Lei $\mathrm{n}^{\mathbf{0}}$. 12.305 de 2010, que institui a Política Nacional de Resíduos Sólidos (PNRS), pois redução, reutilização, reciclagem e disposição final ambientalmente adequada dos rejeitos estão entre os objetivos dessa Política (art. $7^{\circ}$ ). Além disso, esta reconhece como princípio, no Artigo $6^{\circ}$, que o resíduo sólido reutilizável e reciclável é "um bem econômico e de valor social, gerador de trabalho e renda e promotor de cidadania" (Brasil, 2010).

Apesar de ações positivas estarem previstas, não é mostrado um cronograma quanto ao prazo em que as ações serão implantadas, a fonte que irá financiar, o número de pessoas envolvidas, entre 
TABELA 1 - Problemas no âmbito de gestão de resíduos sólidos e soluções propostas por PMSB de municípios da RMRJ.

\begin{tabular}{lll}
\hline Município & \multicolumn{1}{c}{$\begin{array}{c}\text { Principais problemas atuais apontados no PMSB quanto a } \\
\text { resíduos que geram degradação do meio ambiente }\end{array}$} & $\begin{array}{c}\text { Medidas futuras previstas pelo PMSB que podem auxiliar na } \\
\text { diminuição da degradação ambiental por resíduos }\end{array}$ \\
\hline \multirow{2}{*}{$\begin{array}{l}\text { O lixão municipal foi encerrado em } 2011 \text { e ainda não possui projeto } \\
\text { Macacu }\end{array}$} & $\begin{array}{l}\text { de remediação/ Não há coleta seletiva implantada/ Há pontos de do programa do INEA de coleta seletiva solidária; } \\
\text { acúmulos de resíduos domiciliares e lixo jogado pelas ruas nos } \\
\text { bairros Castália, Village (Japuíba), Valério, Setenta/ Acúmulo de lixo } \\
\text { nos balneários em período específico/ Coleta de entulhos é incipiente. }\end{array}$ & $\begin{array}{l}\text { Incentivar a elaboração de políticas públicas para o reconhecimento e } \\
\text { valorização de catadores; } \\
\text { Implantacos programa de coleta seletiva solidária em escolas e órgão }\end{array}$ \\
& &
\end{tabular}

O lixão municipal que operou por 27 anos foi encerrado em $2012 \mathrm{e}$ ainda não possui projeto de remediação. / Não possui hoje área para transbordo dos resíduos domiciliares;

Guapimirim Não há coleta seletiva. /A população joga lixo na rua. / Baixa frequência da coleta de pneus, de entulhos, de folhas/galhos e de depósitos comerciais.

Há acúmulos de resíduos domiciliares e construção civil nas ruas e terrenos baldios, principalmente em bairros afastados do centro.

\begin{tabular}{ll}
\hline Itaboraí & $\begin{array}{l}\text { Não possui informações sobre resíduos sólidos no PMSB do } \\
\text { município }\end{array}$ \\
\hline
\end{tabular}

Elaboração de programas de reciclagem de lixo, com trabalho de coleta e destino final, para geração de emprego e renda para os catadores. / Ampliar projetos de reciclagem existentes, inclusive os de óleo de cozinha usado. / Criar a Cooperativa de Catadores de Lixo, com inclusão social, capacitando os catadores existentes como agentes ambientais.

Não possui informações sobre resíduos sólidos no PMSB do município

Implantação de containers para armazenar os resíduos, evitando Uso dos rios Sarapuí e Pavuna, o Canal do Peri e outros Nilópolis corpos hídricos secundários como depósito de lixo, causando o assoreamento, a degradação ambiental e a contaminação do solo, contribuindo para a proliferação de vetores. aspecto visual negativo e condições sanitárias indesejáveis. / Com prazo até 2019: coleta de resíduos tecnológicos (pilhas e baterias), estocando em barracões de reciclagem até a definição do destino final mais adequado; ampliação dos serviços de varrição de vias e locais públicos. /Limpeza mecanizada de bocas de lobo e tubulações de drenagem urbana/ Programas de Educação ambiental/ Criação do código municipal de resíduos sólidos/Instituições de taxas e tarifas.

O município não possui coleta seletiva e galpão de triagem de recicláveis. Catadores encaminham parte dos resíduos à reciclagem.

Magé Entretanto não há apoio da Prefeitura/ Existem pontos onde o acúmulo de lixo é frequente, sendo considerado um hábito da

Remediação do Lixão de Piabetá/ Implantação do Aterro Controlado Bongaba. população.

Não há nenhum serviço de coleta e destinação final dos entulhos Rio Bonito gerados na construção civil ou de resíduos de poda. / Os pneus são coletados, entretanto, não possuem destinação final adequada, sendo armazenados em um galpão.

Implantação do programa de Coleta Seletiva Solidária do INEA.

Liberação de itens de lixo no rio Imboaçu e acúmulo nas calçadas são justificados pela falta de educação ambiental da população e pela falta de regularidade na coleta de lixo no município/ Não há coleta São Gonçalo $\begin{aligned} & \text { seletiva/ Entulhos são descartados em vários pontos, o que agrava } \\ & \text { os impactos ambientais, uma vez que provocam o assoreamento de }\end{aligned}$ córregos, o entupimento de redes de drenagem e, como consequência, em alguns casos, as enchentes urbanas/ Encerramento do Lixão de Itaoca.

Ampliar o serviço de coleta de resíduos/ Os sacos deverão ser padronizados pela prefeitura municipal e vendidos de forma que a remuneração do serviço de coleta esteja incluída neste valor./ Devem ser escolhidos os recipientes mais apropriados para acondicionamento dos resíduos como, por exemplo, a conteinerização/ Projeto de compostagem/ Projeto Educação ambiental/ Programa de Coleta Seletiva que tem como objetivos não só atender às metas de minimização de resíduos, mas também à inclusão social com geração de postos de trabalho e renda.

Programa terá como apoio uma rede de Ecopontos e Pontos de Entrega Voluntária implantada.

Em 1 a 4 anos, pretende-se promover a coleta seletiva, porta a porta, de forma a atender $15 \%$ da população com uma modesta infraestrutura

São João de Existem pontos onde são despejados os resíduos domésticos de forma Meriti irregular e clandestinamente. para a triagem e tratamento/ Instalação de "Ecopontos" (recitulhos) para o depósito de entulhos. Postos de Entrega Voluntária - PEV/ Desenvolver ações de educação ambiental. / Fomentar e auxiliar a mobilização dos "catadores".

\begin{tabular}{lll}
\hline Tanguá & $\begin{array}{l}\text { Há acúmulos de resíduos sólidos nas ruas/ Município possui } \\
\text { dificuldade na sustentabilidade financeira. }\end{array}$ & $\begin{array}{l}\text { Implantação de novo aterro sanitário com } \\
\text { lagoas anaeróbias) - ainda não operando. }\end{array}$ \\
\hline
\end{tabular}

FONTE: Prefeitura de Cachoeiras de Macacu (2016); Prefeitura de Guapimirim (2016); Prefeitura de Itaboraí (2016); Prefeitura de Magé (2016); Prefeitura de Nilópolis (2013); Prefeitura de Rio Bonito (2016); Prefeitura de São Gonçalo (2015), Prefeitura de São João de Meriti (2015); Prefeitura de Tanguá (2016). 
outros aspectos que causam um questionamento sobre o período em que se pode contar com uma melhoria socioambiental.

Paiva \& Franz (2014) sugerem que, para reduzir a geração de lixo flutuante na $\mathrm{BG}$, sejam implantados programas educacionais que influenciem a população na mudança de hábito; medidas punitivas para quem jogar lixo (como multas); destinação final adequada (incluindo destino para reciclagem, pois, além de diminuir o volume nos aterros, gera renda para os catadores); e maior frequência de limpeza de praias, que somente em Niterói e Rio de Janeiro é realizada pela empresa responsável pelo serviço de limpeza urbana da cidade. Ressalta-se ainda que, nesse estudo, foram entrevistadas 44 pessoas nos bairros de Icaraí, São Francisco e Charitas (município de Niterói) e, ao questionarem os frequentadores sobre o incômodo que sentem em relação ao lixo presente nessas praias, $37 \%$ responderam que são por razões quanto à impressão estética negativa e $12 \%$ por impedir lazer (como banho de mar). Contudo, apesar desses incômodos, apenas $27 \%$ tinham o conhecimento sobre o destino final do seu resíduo. Esse resultado indica que as campanhas de educação ambiental não conscientizam o cidadão de que o destino correto do resíduo pode resultar em uma praia com menor quantidade de lixo flutuante. Franz (2011) destaca que as ações de educação ambiental deveriam esclarecer sobre as implicações do lixo flutuante no cotidiano da cidade e na vida da população.

\section{Conclusão}

A geração de lixo flutuante que atinge a Baía de Guanabara, ou que diretamente é lançada, his- toricamente está relacionada à falta de coleta de resíduos sólidos (ou que ocorre com frequência irregular), à falta de fiscalização quanto ao cumprimento da legislação e à carência de campanhas educacionais exitosas que orientem a população quanto à disposição adequada.

Historicamente, o hábito da população em destinar o lixo em canais ou nas suas margens ocorre desde o século XVII. Desta forma, os canais correspondem a fatores importantes que contribuem para a geração de lixo flutuante desde esse período.

A composição do lixo encontrado no estudo na Baía de Guanabara predominante é de plásticos, que são materiais recicláveis, demonstrando também que é necessário melhorar as políticas de coleta seletiva. Destaca-se, ainda, que produtos de origem doméstica também foram majoritariamente encontrados no estudo. Atualmente estão sendo tomadas medidas paliativas, como, por exemplo, as Ecobarreiras e os ecobarcos, buscando reduzir a poluição por lixo.

Apesar de medidas para o futuro - como o Plano Municipal de Saneamento Básico se apresentar como uma iniciativa passível de resolver os problemas de poluição na Baía de Guanabara, já que melhorias e ampliação dos programas de educação ambiental, coleta convencional e seletiva estão previstas -, entende-se que ainda há falhas nos projetos iniciais a serem corrigidas, como, por exemplo, a apresentação detalhada de como o processo ocorrerá.

Ademais, se espera que esses planos sejam todos entregues até o prazo previsto e sejam executados completamente, contribuindo de maneira eficaz com a despoluição da Baía de Guanabara. 


\section{Referências}

Abreu, M. A. A cidade e os temporais: uma relação antiga. In.: Rosa, L. P.; Lacerda, W.A. (Coord.). Tormentas Cariocas. Seminário de prevenção e controle dos efeitos dos temporais no Rio de Janeiro. Rio de Janeiro: COPPE/ UFRJ, 1997.

Agustin, A. Temporal variability of marine debris deposition at Tern Island in the Northwestern Hawaiian Islands. Marine Pollution Bulletin, 101(1), 200-207, 2015. doi: 10.1016/j. marpolbul.2015.10.076

Aizen, M.; Pechman, R. M. Memórias da limpeza urbana no Rio de Janeiro. Rio de Janeiro: COMLURB, 1985. 132p.

Amador, E. da S. Baía de Guanabara e ecossistemas periféricos: homem e natureza. Rio de Janeiro: Edição do Autor, 1997. 539p.

Amador, E. da S. Baía de Guanabara: ocupação histórica e avaliação ambiental. Rio de Janeiro: Interciência, 2013. 490p.

Araújo, M. C. B.; Costa, M. F. Lixo no ambiente marinho. Ciência Hoje, 32(191), 64-67, 2003. Disponível em: <http:// docplayer.com.br/11846985-Lixo-no-ambiente-marinho. html>. Acesso em: jun. 2015.

Baptista Neto, J.; Fonseca, E. M. Variação sazonal, espacial e composicional de lixo ao longo das praias da margem oriental da Baía de Guanabara (Rio de Janeiro) no período de 1999-2008. Revista da Gestão Costeira Integrada, 11(1), 31-39, 2011. Disponível em: <www.aprh.pt/rgci/ rgci189.html>.

Barreto, A.S. et al. Plano de ação nacional para a conservação dos mamíferos aquáticos: pequenos cetáceos. In: Rocha-Campos, C. C.; Câmara, I. G.; Pretto, D. J. (Org.). Brasília: Instituto Chico Mendes de Conservação da Biodiversidade (ICMBIO), 2010. Disponível em: <http:// www.icmbio.gov.br/portal/images/stories/docs-plano-de-acao/pan-peqs-cetaceos/pan-pequenoscetaceos-web.pdf $>$. Acesso em: ago. 2016.

Bastos, V. P. Construindo Identidades :Catador - Herói ou Sobrevivente da Perversa Forma de Catação? Confluências, 4,1, 2007. Disponível em: <http://www.confluencias.uff.br/ index.php/confluencias/article/view/233>.
Batista, C. A., Roberto, D. M. Diagnóstico da vegetação estação ecológica da Guanabara e região. 2009. Disponível em: <http://observatorio.wwf.org.br/site_media/upload/ gestao/planoManejo/PM_EE_Guanabara 7.pdf $>$. Acesso em: 05 ago. 2016.

Belarmino, P. H. P. et al. Resíduos sólidos em manguezal no rio Potengi (Natal, RN, Brasil): relação com a localização e usos. Revista de Gestão Costeira Integrada, 14(3), 447-457, 2014. doi: 10.5894/Rgci451

Bernardino, D. A poluição por lixo flutuante na Baía de Guanabara: Estudo de Caso do Manguezal no Parque Natural Municipal Barão de Mauá-Magé/RJ. Rio de Janeiro, Monografia (Graduação em Ciência Ambiental) - UFF, 2015.

Brasil. Lei $n^{\circ} 11.445$, de 5 de janeiro de 2007. Estabelece diretrizes nacionais para o saneamento básico. Brasília: D.O.U. de 8.1.2007 e retificado em 11.1.2007.

Brasil. Lei $n^{\circ}$ 12.305, de 2 de agosto de 2010. Institui a Política Nacional de Resíduos Sólidos. Brasília: D.O.U de $3 / 8 / 2010$.

Britto, A. L. Implantação de infraestrutura de saneamento na Região Metropolitana do Rio de Janeiro: uma avaliação das ações do Programa de Despoluição da Baía de Guanabara. Revista Brasileira de Estudos Urbanos e Regionais, 5(1), 63-77, 2003. Disponível em: <http://unuhospedagem. com.br/revista/rbeur/index.php/anais/article/viewFile/2052/2012>.

Conceição, A.; Scotti, M. Lixo no mar. Bem Público, 43, 2013. Disponível em: $<$ http://www.meioambiente.pr.gov.br/ arquivos/File/coea/Revista_Lixo_Marinho.pdf>.

Dias, F. A questão metropolitana. Cadernos Metrópole, 14, 149-174, 2005. doi: 10.1590/8783.

Dossiê de candidatura do Rio de Janeiro à sede dos Jogos Olímpicos e Paraolímpicos de 2016. Volume 1. Rio de Janeiro: Rio 2016, 2009. 34p. Disponível em: $<$ https://www. rio2016.com/sites/default/files/parceiros/dossie_de_candidatura_v1.pdf $>$. Acesso em: 06 ago. 2016.

Eigenheer, E. M. História do lixo. Rio de Janeiro: ELS2 Comunicação. 144, 2009. Disponível em: <http://www. lixoeeducacao.uerj.br/imagens/pdf/ahistoriadolixo.pdf $>$. 
Falcão, P. M.; Souza, C. R, G. Panorama da poluição costeira por pellets de plástico em praias de SP (Brasil): uma contribuição aos Estudos de Geografia do Litoral. In: Anais do VII Congresso Brasileiro de Geógrafos. Vitória/ES, agosto de 2014. Disponível em: $<$ http://www.cbg2014.agb. org.br/<resources/anais/1/1403963697_ARQUIVO_PlinioMartins_TrabCompleto_CBG_VIX..pdfhttp://www. cbg2014.agb.org.br/resources/anais/1/1403963697_ARQUIVO_PlinioMartins_TrabCompleto_CBG_VIX.pdf $>$. Acesso em: 06 ago. 2016.

Febracom/ASSERJ/INEA. Rio ama os rios: ecobarreira. Relatórios de janeiro a dezembro de 2009.

Ferreira, J. L. Comunidades Carentes. Geo-Rio 40 anos: a história, os projetos, o futuro, 11-15, 2006.

Fraiha, S.; Lobo, T. Flamengo. Rio de Janeiro: Fraiha, 1998.

Franz, B. O lixo flutuante em regiões metropolitanas costeiras no âmbito de políticas públicas :o caso da cidade do Rio de Janeiro. Rio de Janeiro, Tese (Doutorado do Programa de Pós-Graduação em Planejamento Energético) - UFRJ, 2011.

Franz, B.; Hartz, A. L. Distribuição de lixo marinho na orla da Baía de Guanabara no município do Rio de Janeiro. In: Anais do Congresso Brasileiro de Oceanografia, Itajaí-SC, 2014. p. 283-284. Disponível em: <http://aoceano. dominiotemporario.com/site//images/pdf/livro_de_resumos_cbo2014.pdf >. Acesso em: maio 2016.

Gamboa, T. Mapas contam a história da Ilha do Fundão. Jornal da UFRJ, Rio de Janeiro, 18, 2007. Disponível em: $<$ http://www.ufrj.br/docs/jornal/2007-abril-jornalUFRJ25. pdf $>$. Acesso em: maio 2016.

Gil, A. C. Métodos e técnicas de pesquisa social. 5 ed. São Paulo, Atlas. 2006, 206 p.

Gomes, I. M. Dois séculos em busca de uma solução: esgotos sanitários e meio ambiente na cidade do Rio de Janeiro. In: Abreu, M. A. Rio de Janeiro, formas, movimentos, representações: estudos de geografia histórica carioca. Rio de Janeiro: Da Fonseca Comunicação, 2005. 254p.

Gregory, M. R. Virgin Plastic Granules on Some Beaches of Eastern Canada and Bermuda. Marine Environmental Research, 10, 73-92, 1983. doi: 10.1016/0141-1136(83)90011-9

Guimba. In: Ferreira, Aurélio Buarque de Holanda. Dicionário da Língua Portuguesa. Edição especial. Curitiba: Positivo, 2008. p. 544.
Hartz, A. L. Cidade Maravilhosa, porém poluida: o caso do lixo marinho na Praia do Flamengo (Rio de Janeiro-RJ). Rio de Janeiro, Monografia (Graduação em Ciências Biológicas) - UFF, 2014.

Holmes, L. A. et al. Adsorption of trace metals to plastic resin pellets in the marine environment. Environmental Pollution, 160, 42-48, 2012. doi: 10.1016/j.envpol.2011.08.052

IBGE - Instituto Brasileiro de Geografia e Estatística. Nota Técnica: Estimativas da população dos municípios brasileiros com data de referência em $1^{\circ}$ de julho de 2014. Disponível em: <http://www.ibge.gov.br/home/presidencia/ noticias/pdf/analise estimativas 2014.pdf $>$. Acesso em: 08 ago. 2016.

INEA - Instituto Estadual do Ambiente. Superintendência Regional Baía de Guanabara. Rio de Janeiro: INEA, 2014. Disponível em: <http://www.inea.rj.gov.br/Portal/ MegaDropDown/Regionais/BaiadeGuanabara/index.htm>. Acesso em: 16 abr. 2014.

Ivar do Sul, J. A. et al. Here, There and Everywhere. Small Plastic Fragments and Pellets on Beaches of Fernando de Noronha (Equatorial Western Atlantic). Marine Pollution Bulletin, 58(8), 1236-1238, 2009. doi: 10.1016/j.marpolbul.2009.05.004

Jeftic, L. et al. Marine Litter: a Global Challenge. Nairóbi: UNEP, 2009. 232 p. Disponível em: <www.unep.org/pdf/ unep_marine_litter-a_global_challenge.pdf $>$. Acesso em: abril de 2016.

Jones, M. M. Fishing Debris in the Australian Marine Environment. Marine Pollution Bulletin, 30, 1, 25-33, 1995.

Laist, D. W. Impacts of Marine Debris: Entanglement of Marine Life in Marine Debris Including a Comprehensive List of species with Entanglement and Ingestion Records. In: Coe, J. M.; Rogers, D. B. (Eds.). Marine Debris: Sources, Impacts and Solutions. New York: Springer Series on Environmental Management, Springer-Verlag, 1997. p. 99-139.

Macedo et al. Materiais compósitos à base de gesso e isopor para construção de casas populares. HOLOS, 27, 15, 2011. doi: 10.15628/holos.2011.658

Mucelin, C. A.; Bellini, M. Lixo e impactos ambientais perceptíveis no ecossistema urbano. Sociedade \& Natureza, 20(1), 111-124, 2008. Disponível em: <http://www.scielo. $\mathrm{br} / \mathrm{pdf} / \mathrm{sn} / \mathrm{v} 20 \mathrm{n} 1 / \mathrm{a} 08 \mathrm{v} 20 \mathrm{n} 1>$. 
Nasser V. L. Estudo da qualidade de água na Baía de Guanabara utilizando técnicas de sensoriamento remoto e análise geoestatística. Rio de Janeiro, Dissertação (Mestrado em Engenharia Civil) - Universidade Federal do Rio de Janeiro - UFRJ, 2001.

Neves, R. C. et al. Análise qualitativa da distribuição de lixo na Praia da Barrinha (Vila Velha - ES). Revista da Gestão Costeira Integrada, 11(1), 57-64, 2011. Disponível em: $<$ http://www.aprh.pt/rgci/pdf/rgci-193_Neves.pdf $>$.

ONU-BR Volume de residuos urbanos crescerá de 1,3 bilhão de toneladas para 2,2 bilhões até 2025, diz PNUMA. Publicado em 06/11/2012. Nações Unidas no Brasil. Disponível em: $<$ https://nacoesunidas.org/volume-de-residuos-urbanos-crescera-de-13-bilhao-de-toneladas-para-22-bilhoes-ate-2025-diz-pnuma/>. Acesso em: 17 jul. 2015.

PAC/PDBG - Projetos Ambientais Complementares/Programa de Despoluição da Baía de Guanabara, 2005. Plano Diretor de Recursos Hídricos da Região Hidrográfica da Baía de Guanabara. Relatório Final - síntese. Rio de Janeiro: Consórcio Ecologus-Agrar, 2005.

Paiva, A. P.; Franz, B. A influência da mídia quanto à geração de lixo marinho: o caso da orla da baía de Guanabara no município de Niterói. Relatório Final (PIBInova), UFF, 2014.

PMSB - Plano Municipal de Saneamento Básico. PMSB. 2016. Disponível em: $<$ https://pmsbguanabara.wordpress. com/pmsb/>. Acesso em: 05 ago. 2016.

Portz, L. et al. Marine debris on Rio Grande do Sul north coast, Brazil: spatial and temporal patterns. Rio Grande do Sul, Revista de Gestão Costeira Integrada, 11(1), 41-48, 2011. Disponível em: <http://www.aprh.pt/rgci/pdf/rgci187_Portz.pdf>.

Prefeitura de Cachoeiras de Macacu. Plano Municipal de Saneamento Básico: água e esgoto, 2016. Disponível em: $<$ https://pmsbguanabara.wordpress.com/pmsb/>. Acesso em: 07 maio 2016.

Prefeitura de Guapimirim. Plano Municipal de Saneamento Básico: água e esgoto de Guapimirim, 2016. Disponível em: $<$ https://pmsbguanabara.wordpress.com/pmsb/>. Acesso em: 07 maio 2016.

Prefeitura de Itaboraí. Plano Municipal de Água de Esgoto do Municipio de Itaboraí, 2016. Disponível em: <https:// pmsbguanabara.wordpress.com/pmsb/>. Acesso em: 07 maio 2016.

Prefeitura de Magé. Plano Municipal de Saneamento Básico: água e esgoto de Magé, 2016. Disponível em: $<$ https:// pmsbguanabara.files.wordpress.com/2015/07/pmsb_mage. pdf Acesso em: 07 maio 2016.

Prefeitura de Nilópolis. Plano Municipal de Saneamento Básico Participativo de Nilópolis, 2013. Disponível em: $<$ https://pmsbguanabara.wordpress.com/pmsb/>. Acesso em: maio 2016.

Prefeitura de Rio Bonito. Plano Municipal de Saneamento Básico: água e esgoto de Rio Bonito, 2016. Disponível em: $<$ https://pmsbguanabara.wordpress.com/pmsb/>. Acesso em: maio 2016.

Prefeitura de São Gonçalo. Projeto: plano municipal de saneamento básico do município de São Gonçalo. Relatório final do PMSB. Dezembro de 2015. Disponível em: <https:// pmsbguanabara.files.wordpress.com/2016/01/pmsb_saogoncalo.pdf>. Acesso em: 07 maio 2016.

Prefeitura de São João de Meriti. Plano municipal de saneamento básico do município de São João de Meriti. Relatório síntese. Julho de 2015. Disponível em: $<$ https:// pmsbguanabara.files.wordpress.com/2014/08/relatorio_sintese_pmsb_meriti.pdf $>$. Acesso em: 07 maio 2016.

Prefeitura de Tanguá. Plano Municipal de Saneamento Básico: água e esgoto de Tanguá, 2016. Disponível em: $<$ https://pmsbguanabara.wordpress.com/pmsb/>. Acesso em: maio 2016.

Prefeitura do Rio de Janeiro. Lei $n^{\circ} 3273$, de 6 de setembro de 2001. Rio de Janeiro: D.O. do Rio de Janeiro de 10/09/01. Disponível em: <http://www.rio.rj.gov.br/ dlstatic/10112/1017211/DLFE-229311.pdf/LegislacaoMunicipal.pdf $>$. Acesso em: maio 2016.

PSAM - Programa de Saneamento Ambiental. Planos Municipais de Saneamento Básico Baía de Guanabara. 2015. Disponível em: $<$ https://pmsbguanabara.wordpress.com/>. Acesso em: 23 nov. 2015.

Quaino, L. Rio 2016: secretaria instala novas ecobarreiras na Baía de Guanabara, 31 de julho de 2015. Disponível em < http://g1.globo.com/rio-de-janeiro/olimpiadas/ rio2016/noticia/2015/07/rio-2016-secretaria-instala-novas-ecobarreiras-na-baia-de-guanabara1.html> Acesso em 30 maio 2016. 
Rezende, S.C., Heller, L.H. O saneamento no Brasil: políticas e interfaces. 2. ed. revista e ampliada. Belo Horizonte: Editora UFMG, 2008.

Rio 2016. Plano de Gestão da Sustentabilidade dos Jogos Rio 2016 ${ }^{\mathrm{TM}}$,- versão 1, Março 2013 -. Disponível em: $<$ http://www.rio2016.com/sites/default/files/Plano_Gestao_Sustentabilidade_PT.pdf $>$ Acesso em 05 Set. 2015.

Rio 2016. Abraçando mudanças Relatório de Sustentabilidade Rio 2016. Rio de Janeiro: Comitê Organizador dos Jogos Olímpicos e Paralímpicos Rio 2016, 2014. Disponível: < https://www.rio2016.com/transparencia/sites/default/ files/relatoriodesustentabilidade_rio2016_set2014.pdf>. Acesso em: Maio de 2016.

Rio de Janeiro. Lei $n^{\circ}$ 4.191, de 30 de setembro de 2003. Dispõe sobre a Política Estadual de Resíduos Sólidos e dá outras providências. Rio de Janeiro: D.O. de 02/10/2003.

SEA - Secretaria Estadual do Ambiente. Avisos: PSAM. Rio de Janeiro: INEA, 2013. Disponível em: $<$ http://www. rj.gov.br/web/sea/exibeconteudo? article-id=926885>. Acesso em: jun. 2015

SEA - Secretaria Estadual do Ambiente. Sistema de operação de ecobarcos e ecobarreiras será readequado, 2015. Disponível em: <http://www.rj.gov.br/web/sea/ exibeconteudo? article-id $=2352695>$. Acesso em: maio 2015.

Silva, R. N.; Oliveira, R. Os limites pedagógicos do paradigma da qualidade total na educação. In: Anais Eletrônicos do IV Congresso de Iniciação Cientifica da UFPE. Recife, 1996. Disponível em: <https://www.ufpe.br/conic/>.

Souza, H. Uma agenda permanente para o poder público e a sociedade. In: Rosa, L.P.; Lacerda, W. A. (Coord.). Tormentas Cariocas. Seminário de prevenção e controle dos efeitos dos temporais no Rio de Janeiro. Rio de Janeiro: COPPE/UFRJ. 1997.

Takada, H. Call for pellets! International Pellet Watch Global Monitoring of POPs using beached plastic resin pellets. Marine Pollution Bulletin, 52, 12, 1547-1548, 2006. doi: 10.1016/j.marpolbul.2006.10.010.

Teixeira, M. G. C.; Bessa, E. S. Estratégias para Compatibilizar Desenvolvimento Econômico e Gestão Ambiental numa Atividade Produtiva Local. Revista Administrativa de Contemporânea, 13, Edição Especial, 1, 1-18, 2009. doi: 10.1590/S1415-65552009000500002

Tucci, C. E. M. Urban Waters. Estudos Avançados, 22, 63, 2008. doi: 10.1590/S0103-40142008000200007

UNEP - United Nations Environment Programme. Marine Litter: An analytical overview. Nairóbi: UNEP, 2005. p. 47. Disponível em: <http://www.unep.org/regionalseas/ marinelitter/publications/docs/anl_oview.pdf $>$. Acesso em: maio 2016.

UNEP - United Nations Environment Programme. Abandoned, lost or otherwise discarded fishing gear. 2009. Disponível em: < http://www.unep.org/regionalseas/ marinelitter/publications/docs/Marine_Litter_Abandoned_Lost_Fishing_Gear.pdf $>$. Acesso em: 04 ago. 2016.

Vedollin, M. C. Estudo da distribuição de metais em plásticos no Litoral de São Paulo: avaliação da poluição por meio da análise de pellets. São Paulo, Dissertação, (Mestrado em Oceanografia) - USP, 2014.

Vieira, B. P. et al. Homogeneidade de encalhe de resíduos sólidos em um manguezal da Ilha de Santa Catarina, Brasil. Revista da Gestão Costeira Integrada, 11(1), 21-30, 2011. Disponível em: <http://www.aprh.pt/rgci/pdf/rgci188_Vieira.pdf>. 